\title{
Mental Health Care Given to Children and Adolescents in the Center for Children and Your Psychosocial: From the Perspective of Health Professionals
}

\author{
Máguida Gomes da Silva, Ana Ruth Macêdo Monteiro, Katyuscia Morais Barros, \\ Sarah Maria de Sousa Feitoza, Violante Augusta Batista Braga, \\ Cristiana Brasil de Almeida Rebouças \\ Department of Nursing, Universidade Estadual do Ceará, Fortaleza, Brazil \\ Email: enfamag@yahoo.com.br
}

Received 12 October 2014; accepted 13 June 2015; published 17 June 2015

Copyright (C) 2015 by authors and Scientific Research Publishing Inc.

This work is licensed under the Creative Commons Attribution International License (CC BY).

http://creativecommons.org/licenses/by/4.0/

(c) (i) Open Access

\begin{abstract}
This study was carried out in order to investigate the professionals' feelings concerning the care in the Center for Children and Youth Psychosocial Care, as well as to evidence the advantages and difficulties of this work. This was a qualitative research guided by the social phenomenology of Alfred Schütz. 13 health professionals from CAPSi between November 2008 and January 2009 were interviewed. We identified three categories: First feelings, difficulties of care and motivation for the care. The first category, awakened feelings, relates to the beginning of work with children and adolescents in CAPSi. The second motivation for the care, relates to the points highlighted as conducive to work. The third, difficulties in Caring for expressing the difficulties encountered in mental health of children and adolescents in CAPSi. We concluded that the care depends of knowledge, experience and service conditions in order to attend the needs of children and adolescents in CAPSi.
\end{abstract}

Keywords

Child Care, Children, Adolescent, Mental Health, Nursing

\section{Introduction}

The care in mental health children and adolescents is very important, thus, the health professional must be prepared to face the challenges of dealing with these patients, integrating several factors such as family, community, 
environment, culture and beliefs.

Assessing the mental health of this population has a differential: requires to be considered the characteristics of the development of the child and/or adolescent with environmental changes, despite a clearly defined line does not exist between normal and pathological this population for her to meet in full development [1].

In order to meet this public needs, specific public services were implanted, denominated as Centros de Atenção Psicossocial Infanto Juvenis (CAPSi) that constitute devices for deinstitutionalization through the reintergration of the subject in psychological distress (user) into society and comprehensive care, with the purpose of not reproducing the service asylums [2].

The purpose of this new deinstitutionalizing care model was based on an individualization of treatment and liaison with different outpatient services, such as therapeutic homes, clinics, beds in general hospitals, workshops on income generation, etc. [3].

In assisting children and adolescents to care these principles are used as subject of responsibilities and rights, among these are the right to the care, aiming at uniqueness, respecting their subjectivity, locating a person in distress and implications in psychic events in which case [4].

The relationship between health professional and the child or the teen under psychological distress is grounded in through responsibility and respect, developed, for example, during the activities in CAPSi, such that, in the world of everyday life, professional and user come into a mutual relationship and try to understand each other as well as themselves through the experiences that constitute them. In social relations there is a meeting of subjects in a face-to-face relationship, because this way, it is possible to perceive and know each other, capturing its action subjectively meaningful in the world life [5].

Thus, the objectives of this study were investigating the feelings of professionals in relation to mental health care in CAPSi and highlighting the strengths and difficulties in caring.

\section{Methods}

\section{Study Desing and Participants}

This is a study of descriptive and exploratory, being qualitative in nature, since it required a set of interpretive practices and materials that give visibility to the world, transforming it and making it a series of representations. This research involves an interpretive, naturalistic approach of the world, seeking to understand or interpret phenomena in terms of the meanings people attribute to them [6].

The study site was the reference service in mental health for children and adolescents in psychological distress, called CAPSi belonging to the Executive Secretariat of the IV Regional Municipality of Fortaleza, Ceará.

The research subjects were higher education and technician levels professionals in health area who were working in CAPSi and had at least six months experience, long enough for the professional to be familiar with the service and the care to children and adolescents in psychological distress, thus having better insight about their experience at the institution. The professionals who did not come to CAPSi, as date and preferred time of the subject or those which did not allow new schedule were excluded.

The data production was between November 2008 and January 2009. The interview and form were the methods used. Interviewees were given names of precious stones and so they are represented in this article.

The interview, in the phenomenology of social relations, is configured in a mutual relationship between the researcher and the researched as to the communicator and to whom it is directed, and hence the appearance of a face-to-face relationship, where there is knowledge and perception of the other, capturing subjectively meaningful action in the world live of each other [5].

In this face-to-face relationship, each participant shares with the other, which is your neighbour, i.e. the one with whom you have a direct experience, a vivid present their knowledge at hand. Thus, each one is also an element of the other's environment and, both participate in a range of experiences of the external world [5].

All professionals who met the inclusion criteria were invited to participate in the research, but two did not attend on the date scheduled by them to collect the data, nor was a new schedule booked. Thus, the interview was conducted with 13 of the 15 health professionals including technical and higher level.

The participants were informed about the research and about its goals, and they signed an Informed Consent Statement. Likewise, they agreed with the recording of the speeches in MP3, to ensure the accuracy of reports.

For data analysis the analysis of thematic categories was used, starting after the data collection and using the transcripts of the interviews, which were read and reread, with their diffuse excerpts being cleared to then be 
organized into thematic categories according to the subjects that resembled the speeches presented, comparing each interview with the following one, facilitating comparison between the deponents [6].

Subsequently, there was a comprehensive analysis of the speeches according to the concepts of Alfred Schütz Social Phenomenology, which prioritize human experiences in their action and interpretation of the "world o life" [5], where each person develops his/her own "world" and at the same time, believes in the possibility of sharing experiences of ordinary meanings. The research was approved according to the second process 07157886-2, FR: 132704.

\section{Results}

The health professionals who participated in the survey made up a total of 13 interviewees, of whom seven had postgraduate in Mental Health and/or children-youth area. Their ages ranged 25 - 52 years, from these eight were married and five single, and four were men and nine were women. The working time at CAPSi ranged between six months and four years, according to the inclusion criteria.

Based on the analysis of the interviews, the following categories were perceived: awakened feelings, motivation for the care and difficulties in caring.

\subsection{Awakened Feelings}

The first category, awakened feelings, is related to early work with children and adolescents in CAPSi. It glimpses the motivations for starting work with mental health of children and adolescents, as well as exposure of feelings such as concern, caution, anxiety or even pleasure to tackle something new, like the work with such specificity promoted by the served age group.

I wanted to work with children and teens when I went to the hospital and saw the sufferings of them there, the way they were treated was so... I dunno, kind of rude, and I thought this an absurd. So, I promised I would do the nursing course and work taking care of these children. Especially because I had children and I only remembered them (ALEXANDRITE).

I thought that working in mental health with children was a challenge, because I liked it, an obligation, but after I took psychotherapy sections, I realized I did not. I realized that taking care of these children in these situations, healing their pain, I was reframing my pain in the past, the pain suffered by a child for being a son of a castrating father and a wonderful mother, for living this social bipolarity (TOPAZ).

According to the testimonials, facts of the past of both professionals, being recent, as witness mistreatment in hospitals, or more remote, as the experiences of his/her own childhood, were significant in the choice to work in CAPSi. Even motivated by particular experiences, the experience of working with children and adolescents in psychological distress exalts some feelings of insecurity, such as fear and anxiety.

At first I was scared because they were schizophrenic children. I spoke with them and they did not answer me, some wanted to attack you and others were aggressive (RUBY).

Actually ... I did not feel any fear. I usually do not fear, because I like challenges and working with children was one more challenge of my life (DIAMOND).

Considering working with children and adolescents in psychological distress in its specificity, some professionals stood in relation to the issue as a challenge to be faced.

At first I felt some concern, yes! But I did not feel anxiety because always when a patient I do not know came; I got worried because I had a feeling I cannot give proper treatment, to frustrate me. But this I faced very well (TUORMALINE).

There is a longing that the requirements set by the customer could not be met, so that the concern and care were cited as allies in the search for the best way to professionals, even for those with some experience in working with children.

I tried to be more careful, but I felt no fear or anxiety. As I had previously worked with children, even if not with a mental disorder, but I knew the world was with them a bit. (JADE).

Prior knowledge of the professional, on how to deal with children, contributed to reduce fear and anxiety, according to the testimony.

\subsection{Motivation for the Care}

The second category, called motivation for the care, is related to the points highlighted as favourable to work 
with this type of clientele. The interviewees' answers were varied, citing, for example, conducive work environment, the vocation to this function, the feeling of accomplishment and a taste for continuous learning at work.

Thus, some testimonials show how caring at CAPSi is pleasurable and rewarding. The feelings of love and contentment were expressed in both lines, as on the faces of the professionals.

The people are wonderful, the work environment is pleasant, accessibility contributes a lot to me and I especially like working with children, because I got a childish soul (ONYX).

The advantage is that I love it here, I always wanted to work with children... I like to give love and receive love, they are very affectionate, the parents are also wonderful (ALEXANDRITE).

I love working with children, infant Caps is part of my life (DIAMOND).

It was evident the will of the interviewed professionals in working with children, not only through their statements, but also their facial and body expressions, stating this will and pleasure to care and to be near children and adolescents accompanied there. Thus, it was perceived the professional satisfaction in being there at that institution and being useful to it and to its users. It is impossible not noticing the smile of the interviewees before verbally express the benefits of being in that environment.

The biggest advantage that I see is that they can carry out the activities that we pass, for example, in my therapy group we composed a song with lines spoken by each participant (BENITOITE).

The main advantage is that we are always learning more, learning about mental health, getting to know these children, these adolescents and their families better and we can help them in their suffering, here I feel myself useful (DEMANTOID GAMET).

The professional achievement expressed by the two former statements, both through satisfactory performance of users in activities at CAPSi, concerning to the continuous learning of the professional it may awaken the search for more knowledge about the performance of their duties at CAPSi.

\subsection{Difficulties in Caring}

The third category was named difficulties in caring for expressing the difficulties encountered in mental health of children and adolescents at the CAPSi studied. Professionals presented their opinions clearly and consciously, without the intent to obscure the difficulties that need to be overcome to improve the assistance to users. The physical space was cited as a factor that hampers the work in CAPSi. The infant Caps works on a rented place and its physical structure is a residential house adapted to attend the patients, according to information from some professionals. The institution is comprised of five juxtaposed rooms where, in the centre, there is a hall for the reception, followed by the kitchen and cafeteria. There are also rooms for a pharmacy, a nursing and one more for performing groups, lateralized by a small garden.

The physical space is very limited, few rooms, you know... there is not much privacy, the playful arsenal is also precarious, I think that's all (AMETHYST).

The lack of recreational resources was also pointed out by interviewees in this category. Musical instruments, books, toys, material for crafts, colouring material, children's decorations in the rooms and other facilities of the institution have become scarce and are considered important for them to be used as facilitators in interaction with children and adolescents, and useful to be employed in activities that work communication, perception, curiosity.

Well, when talking for the child, I miss the recreational resources, because this will help in his/her interaction with us, and the child is also dependent on the family and we need this family help and as it often happens a distance from parents (TOPAZ).

The family takes on a role of great importance in child care, because on it rests the responsibility with the physical, emotional and social well-being of its members. The child is dependent on his caregiver or guardian having not, in most, autonomy and judgment to come and go, or to be responsible for treatment. Thus, CAPSi professionals have the commitment of family members to accompany the child or adolescent to monitor the treatment in the institution.

The child is still dependent on parents or guardians to come to CAPS. So, we have to excel commitment by parents about it, because if they do not bring kids it is difficult to continue treatment (SAPPHIRE).

The expression of difficulties linked to the management of medications in CAPSi was cited by pharmacists who have left obvious the obstacles to the maintenance of drugs in sufficient quantity for its users as well as the 
longing for improvement in the quality of the service.

The main difficulty I have in my activity is the lack of medicines because the bidding processes are time consuming (DIAMOND).

The difficulty I find is the lack of training for us to make a proper pharmaceutical care (RUBY).

The lack of drugs in the institution, although it is not common, is causing discomfort to manage the pharmacy at CAPSi. In order to not interrupt the pharmacological treatment of children and adolescents, the pharmacist proposes himself to guide the user about another way of getting it, fact that demand time and family wear to go to another environment in the search for drug.

Even with all the difficulties reported by professionals working at CAPSi, the best way to meet the needs of users in a creative way and based on an individualized treatment plan is sought.

\section{Discussion}

In the awakened feelings category it is realized that interest in caring for children and adolescents may be related to previous experiences, which boosted professionals seeking to engage in work with this age group.

The accumulation of experiences from childhood, plus other ones throughout life constitutes the body of knowledge, which, according to Schütz, is called knowledge at hand. It is before it that the individual perceives and interprets the events of his/her daily life and relies for a future action.

Arising in the professional the eagerness to become caretaker, the images of abuse witnessed in past experiences were considered, and that in this vivid present, taking care of children and adolescents in the best possible way, allows one to rescue the opportunity to provide a treatment that is considered satisfactory.

Some professionals reported fear at the beginning of the mental health work with children and adolescents, particularly those who had not yet had the experience with such age, but considered it challenging.

The contact of health professionals directly with the new and unknown, as presented in testimony by the fear of not knowing how to act in the face of psychological distress presented, can produce feelings of anxiety as they see their professional identity put into question [7].

A study argues that the perception of nurses as a little prepared technically professional to act against the psychic demands of the patient, is one of the factors that complicates the practice in CAPS [8].

Thus the practice in mental health is immersed in doubts, especially with regard to the "what to do" in mental health. It is like there is a gap, requiring daily flexibility of the worker. However, these irregular contours are going to assuming an innovative character to the practice, not only with the incorporation of new tools and ways of working, but also to the care provided in all settings of CAPS [9].

Those professionals with previous experience in working with children were safer for the performance of their functions in CAPSi. This knowledge as part of their set of knowledge at hand can be used as a guide to the necessary attitudes toward mental health care users to the same age group.

The man constitutes his collection of experiences from the inheritance, the daily experience, the multiple influences of tradition, habits and his forethought [9]. Although his knowledge of everyday life has only approximate or typical character, habits, rules and principles, which regularly apply successfully are assumptions that satisfy the requirements of the moment of action and are strong bases for the performance of life.

In the motivation to care category was perceived that for professionals working in CAPSi there are several advantages in working with mental health of children and adolescents. These permeate both the physical realm, such as accessibility, as emotional like the pleasure in working with children and see success in your work.

Therefore, it is care technology in mental health care that is independent of specific skills, because it involves feelings inherent to the human condition, such as affection, availability, generosity and interest in the other [9].

Studies with nurses show favourable results of this work, among which stand out the independence of the patient for self care, improved self-esteem and maintain good personal appearance, improved interpersonal relationships and the reduction of hospital readmissions [10].

Moreover, these professionals can provide support and make the familiar subject of care by implementing the treatment plan for the users and identify the needs of the family regarding on how to deal with the individual in psychological distress at home [2].

Due to the success in working with children and adolescents in psychological distress, professionals' actions can be stored in a positive way in the stock of knowledge at hand and reapplied in his job, later, through the observance of each case. 
Thus, human action is linked to the stock of knowledge, the result of previous experiences, typically similar to those projected, and which act as a frame of reference, the recipes for their action and interpretation of the world [5].

The professional feels useful; visualizing the results achieved with the mental health care and instigates himself to be looking for new knowledge to his practice. The CAPSi then becomes place of study, to share knowledge among professionals.

Constant learning is also cited as an advantage in working in CAPSi, but it should be added that the narratives of life of children and adolescents who are attended at CAPSi as well as the daily contact with them, also add to the scientific knowledge of these professionals assisting them in their work.

In the difficulties of caring category the interviewees have referred to their work in CAPSi the limited physical space, the tiny amount of recreational resources and obstacles to maintaining the stock of medications. Family participation in care for children and adolescents was highlighted as critical to the continuity of care.

The physical structure of the site, adapted from a home with some rooms, is getting smaller for the growing demand of children and adolescents in psychological distress attended at CAPSi, not meeting the needs of most users; especially during the rainy season, when access to the two rooms that are in the back of the property is impaired, so that sometimes professionals do not have place to attend children and adolescents.

Observing the structure of the place, it was noticed that also has no room to the recreation of children as a playground, although there is room for it, and a few playful motifs such as paintings or prints on the walls, as decorative pieces. Similarly, the CAPSi has some toys, games, craft material, but the amount is still insufficient to meet users demand.

Regarding the pharmaceutical practice, this involves health education, pharmaceutical orientation, dispensing and pharmacotherapeutic following, beyond the systematic recording of activities, measurement and evaluation of results. Obviously the psychosocial care implies new practices that go far beyond medication. However, medication is needed for the reduction of symptoms with the purpose of assisting the individual to regain or rebuild his life project, participate in activities that develop their skills, their autonomy and promote his reintegration into society [11].

Thus, the difficulties encountered by pharmacists in their practice represent an obstacle, not only to this professional, but also hamper the continuation of therapeutic plan for children and adolescents who are on medical therapy, since the family is encouraged to get medication in different health, demanding more time of the caregiver.

The family is also important in the care of children and adolescents in psychological distress, with regard to the conduction to the CAPSi and support for user maintenance at home. Indeed, practitioners mentioning the importance of the family for obtaining success in the care.

Working with family and society has effective value in integrating user to daily activities. This work, among other programs, is recommended by the Ordinance of the Assistance Secretary of the Ministry of Health, the World Health Organization since 1964.

The attention of the Family Health Team, however, should also be preventive because there is a risk of the caregiver initiates a process of psychological distress in the face of stressful factors in coping with psychological distress [12].

Thus, the health professional should understand that the family is also affected by psychological distress of children and adolescents in their home, and the attitude of professionals should not only be to inform the importance of family support, but also provide conditions for it promotes this care.

This will make sure that mental health characterized by individual, group and environment capacities interacts to form as to promote optimal development and use of mental abilities [13].

\section{Limitation and Recommendations for Futures Studies}

This study is limited by the samplesize was small for the collection of data, requiring realizer future studies with other institutions to analyze the importance Mental health of children and teenagers in psychic suffering.

\section{Conclusions and Clinical Implications}

Working with mental health of children and adolescents requires more attention from healthcare professionals, not only by the increased demand, but also by the need to overcome the obstacles that surround this service. 
Therefore, this research is devoted to investigating the feelings of professionals in relation to mental health care in the CAPSi and to highlight advantages and difficulties in caring.

In consequence of the results presented and discussed in the light of the phenomenology of social relations, it is intended to support professionals dedicated to these clients in their care, showing them their route in categories: feelings awakened motivation for the care and difficulties in caring and helping them in thinking about their care.

Interviewees demonstrate interest by the clientele because of successful events held in their world of life. These experiences may come from within the family or in everyday attitudes witnessed by the individual, as in statements obtained, building up and joining the scientific knowledge acquired by professionals in order to act in their care with attitudes that served to a typical considered correct to care for children and adolescents in psychological distress.

It was apparent that the knowledge at hand reported by previous experience in professional care to children and adolescents, even though these were not in psychological distress, they collaborated in performing their functions in CAPSi. These professionals were more confident in their activities, performing them using as reference the knowledge at hand acquired in the world of everyday life.

At CAPSi, the team constantly meets to discuss about assistance to users. So what professionals absorb as attitudes that can be used successfully in working with this clientele becomes knowledge at hand.

These attitudes may be considered by professionals as essential to children and adolescents in mental suffering, so that aims to meet a need that is typically present in these users.

Before what professionals consider typical of children and adolescents, interviewees pointed as difficulties to care the inadequate physical structure of CAPSi and the lack of recreational resources to develop activities deemed important for accompanying in mental health.

Adherence to treatment is bound by the deponents, to the family components. These are of great importance in commuting between home and the CAPSi, to the assistance for the needs of children and adolescents as well as for monitoring the drug treatment. The family, however, needs support in living with the specifics of children and adolescents in psychological distress and are also vulnerable to the development of psychological distress as a result of the difficulties faced in everyday socializing. Thus, the mental health team must be attentive to the care not only of children and adolescents in psychological distress, but also able to support the family in care at home.

\section{Conflict of Interest}

No conflict declared.

\section{Acknowledgements}

We would like to thank all participants in the study.

\section{References}

[1] Arrué1, A.M., Neves, E.T., Terra, M.G., Magnago, T.S.B.S., Jantsch, L.B., Pieszak, G.M., Silveira, A. and Buboltz, F.L. (2013) Crianças/Adolescentes com necessidades especiais de saúde em Centro de Atenção Psicossocial. Revista de Enfermagem da UFSM, 3, 227-237. http://dx.doi.org/10.5902/217976927827

[2] Machineski, G.G., Schneider, J.F. and Camatta, M.W. (2013) O tipo vivido de familiares de usuários de um centro de atenção psicossocial infantil. Revista Gaúcha de Enfermagem, 34, 126-132. http://dx.doi.org/10.1590/S1983-14472013000100016

[3] Ministério da Saúde (BR) (2004) Legislação em saúde mental 1990-2004. 5th Edition, Ministério da Saúde, Brasília (DF).

[4] Brasil. Ministério da Saúde (2005) Secretaria de Atenção à Saúde. Departamento de Ações Programáticas Estratégicas. Caminhos para uma política de saúde mental infanto-juvenil/Ministério da Saúde, Secretaria de Atenção à Saúde, Departamento de Ações Programáticas Estratégicas. Série B, Textos Básicos em Saúde, Editora do Ministério da Saúde, Brasília, 76 p.

[5] Schutz, A. (2012) Sobre fenomenologia e relações sociais. Vozes, Petrópolis.

[6] Flick, U. (2009) Desenho da pesquisa qualitativa. Artmed, Porto Alegre, Análise dos dados qualitativos, 131-140.

[7] Koda, M.Y. and Fernandes, M.I.A. (2007) A Reforma psiquiátrica e a constituição de práticas substitutivas em saúde 
mental: Uma leitura institucional sobre a experiência de um núcleo de atenção psicossocial. Cadernos de Saúde Pública, 23, 1455-1461. http://dx.doi.org/10.1590/S0102-311X2007000600020

[8] Vargas, D., Oliveira, M.A.F. and Duarte, F.A.B. (2011) A inserção e as práticas do enfermeiro no contexto dos Centros de Atenção Psicossocial em Álcool e Drogas (CAPS AD) da cidade de São Paulo, Brasil. Revista Latino-Americana de Enfermagem, 19, 115-122. http://dx.doi.org/10.1590/S0104-11692011000100016

[9] Pinho, L.B., Rodrigues, J., Kantorski, L.P., Olschowsky, A. and Schneider, J.C. (2012) Desafios da prática em saúde mental na perspectiva do modo psicossocial: Visão de profissionais de saúde. Revista Eletrônica de Enfermagem, 14, 25-32. http://dx.doi.org/10.5216/ree.v14i1.14352

[10] Bressan, V.R. and Scatena, M.C.M. (2002) O cuidar do doente mental crônico na perspectiva do enfermeiro: Um enfoque fenomenológico. Revista Latino-Americana de Enfermagem, 10, 682-689. http://dx.doi.org/10.1590/S0104-11692002000500009

[11] Kantorski, L.P., Hypolito, A.M., Willrich, J.Q. and Meirelles, M.C.P. (2010) A atuação do enfermeiro nos centros de atenção psicossocial à luz do modo psicossocial. REME—Rev. Min. Enferm, 14, 399-407.

[12] Silva, M.B.C. and Sadigursky, D. (2008) Representações sociais sobre o cuidar do doente mental no domicílio. Revista Brasileira de Enfermagem, 61, 428-434. http://dx.doi.org/10.1590/S0034-71672008000400005

[13] Vidal, M.R., Salas, M.C., Escobar, V.S., Utreras, A.V. and Arriagada, J.M. (2011) Calidad de vida en pacientes Esquizofrénicos. Año, 11, 66-76. 